OCTREOTIDE DECREASES GASTRIC MUCOSAL BLOOD FLOW : A CONTROLLED ASSESSMENT BY LASER DOPPLEER FLOMETERY.

A K K KUBBA, G H HAYDON , P C HAYES , K R PALMER WESTERN GENERAL HOSPITAL \& THE ROYAL INFIRMARY OF EDINBURGH

The somatostatin analogue octreotide has been used to stop peptic ulcer haemorrhage, although its mochanism of action is unclear. It may exert an effect by reducing gastroduodenal mucosal blood flow.

Mucosal blood flow was measured using a Laser

Doppler Flowmeter. The Doppler probe was positioned in the upper gastrointestinal tract (either endoscopically or via a small gastrostomy) of seven rabbits. Preliminary experiments showed the method to be reproducible, non invasive and simple.

Mucosal blood flow was decreased in a dose dependent manner in the body (193.5U to 71.25U) and antrum (154.8U to $34.7 \mathrm{U}$ ) of the stomach and duodenum(187.5U to 67.5U) by doses of octreotide ranging from 10-50 microgram $/ \mathrm{kg}$ of body weight. The change was not associated with systemic haemodynamic changes. Vasopressin(1 microgram/kg) but not normal saline also reduced gastroduodenal mucosal blood flow , but this was associated with profound bradycardia and a fall in non gastrointestinal tissue perfusion Gastroduodenal mucosal blood flow is reduced in a dose dependent manner by octreotide suggesting that this agent may be helpful in the management of bleeding from gastroduodenal ulcer disease and gastritis

Experimental studies of iniection therany for ulcer
haemorrhage in rabbits
Kubba A K , Palmer K R
Gastro-intestinal Unit, Western General Hospital
Edinburgh, Scotland.
Endoscopic injection therapy is a well established
method of controlling peptic ulcer haemorrhage but
the optimum solution and the mechanism involved in
inducing haemostasis are unknown . Efficacy and
tissue effects of various therapeutic agents in the
control of gastric mucosal haemorrhage were studied
in 10 rabbits . Forty bleeding mucosal ulcers created
at gastrotomy (Blood loss > 1.5 ml/min) were studied
Adrenaline(1:100,000), thrombin, fibrin(thrombin
plus fibrinogen), $5 \%$ ethanolamine and $50 \%$ dextrose
were injected into the bleeding ulcers.
Sclerosants were found to be least effective in the
control of bleeding and were associated with
significant tissue necrosis . Although all the other
solutions significantly decreased blood loss within 30
minutes of injection therapy (median blood loss
=0.25mlmin), only a mixture of adrenaline plus
thrombin and sprayed fibrin achieved complete
haemostasis within 2 minutes of treatment and with
no recurrence of bleeding . Neither modality caused
significant tissue damage .
Histological examination showed that no injected
solution caused arterial thrombosis when injected next
to a major ear artery .
We conclude that a combination of dilute adrenaline
plus human thrombin may represent optimal
haemostatic therapy for peptic ulcer haemorrhge

\section{Stomach and bleeding F254-F258} F254

ANTIBIOTIC TRANSFER ACROSS THE GASTRIC MUCOSA AN IN VITRO MODEL. AF Goddard \& RC Spiller. Division of Gastroenterology, University Hospital, Nottingham. NG7 .2UH. UK

Introduction The mechanisms underlying transfer of antimicrobial agents for the treatment of $H$. pylori across the gastric mucosal barrier are poorly understood. An in vitro model was designed and validated to investigate these mechanisms.

Methods Gastric corpus mucosa was obtained from male Wistar rats $(300-350 \mathrm{~g})$, stripped of muscle layers, mounted in Ussing chambers and bathed in oxygenated Krebs solution. Metronidazole or amoxycillin were added on either side of the mucosa and timed samples taken from the opposite side. Antibiotic concentrations were measured using HPLC. Metronidazole flux from serosa to mucosa $\left(J_{S \rightarrow M}\right)$ was measured ( $n=8$ for each experiment): 1) under basal conditions; 2) compared with mucosal to serosal flux $\left.\left(J_{M \rightarrow S}\right) ; 3\right)$ in chambers of different cross-section; 4) with stimulation by $100 \mathrm{mM}$ histamine and carbachol; 5) in comparison with amoxycillin flux under basal conditions. $J_{\mathbf{M} \rightarrow \mathbf{S}}$ for metronidazole was measured with mucosal $\mathrm{pH}$ at 2.2, 2.7, 3.2 and 7.4.

Results Reservoir concentrations varied between 0.2 and $0.4 \mathrm{mM}$ between but not within each experiment and were correlated $(\mathrm{P}<0.001)$ with metronidazole flux. Flux results are expressed as mean (SEM) in $\mu \mathrm{mol} . \mathrm{cm}^{-2} \cdot \mathrm{hr}^{-1}:$ 1) Metronidazole $J_{\mathrm{S} \rightarrow \mathrm{M}}$ was 48.9 (8.7) under basal conditions; 2) $J_{S \rightarrow M}$ was 79.2 (13.5) compared with $J_{M \rightarrow S}$ of 98.3 (37.3) $(\mathrm{P}=\mathrm{NS})$; 3) $J_{S \rightarrow M}$ with a chamber diameter of $1.2 \mathrm{~cm}$ was 39.8 (2.4) and 40.8 (5.8) with a $0.9 \mathrm{~cm}$ diameter $(\mathrm{P}=\mathrm{NS})$; 4) $J_{\mathrm{S} \rightarrow \mathrm{M}}$ was 68.2 (6.2) with stimulation and 73.4 (4.6) without ( $\mathrm{P}=\mathrm{NS})$; 5) metronidazole $J_{\mathrm{S} \rightarrow \mathrm{M}}$ was 39.8 (2.4) compared to amoxycillin $J_{\mathrm{S} \rightarrow \mathrm{M}}$ of 22.4 (2.4) (P<0.01). When mucosal $\mathrm{pH}$ was changed, $J_{M \rightarrow S}$ was proportional to the unionised concentration on the mucosal side $(\mathrm{P}<0.001)$.

Conclusions Metronidazole transfer across the gastric mucosa occurs by simple diffusion and $\mathrm{pH}$ partition occurs on the mucosal side. This model shows selectivity for difierent antibiotics and will be useful for the study of other therapeutic agents in the treatment of $H$. pylori.

AFG is in receipt of an Astra Research Fellowship.
F256

ROLE OF TIPSS IN THE MANAGEMENT OF GASTRIC VARICEAL HAEMORRHAGE.

K.I. Bzeizi, A.J. Stanley, R. Jalan, D. Redhead, K. Simpson, P.C. Hayes, Centre of Liver and Digestive Diseases, Royal Infirmary of Edinburgh

Bleeding from gastric varices is associated with a high risk of early rebleeding and mortality. We assessed the impact of transjugular intrahepatic portosystemic shunt (TIPSS) on the management of bleeding from gastric varices and compared this to the treatment prior to introduction of TIPSS. A total of $\mathbf{4 2}$ patients were referred with gastric variceal bleed during the period 1989-1995. 39 were considered for analysis. 30 patients $(12$ males, 18 females, mean age = 49.1 years) with Child B cirrhosis had TIPSS inserted after their initial bleed (group I). Group II patients ( 6 males, 3 females) referred before TIPSS was available, were treated either endoscopically (6 patients) or by surgery ( 1 spleno-renal, and 2 had oesophageal transection with splenectomy).

Both groups were matched for age and Child score. Mean portal pressure gradient (PPG) was reduced from $13.1 \pm 1.42$ to $6.3 \pm .82$ $\mathrm{mmHg}(\mathrm{p}<0.01)$ post TIPSS. Over a mean follow up of 18.1 months, rebleeding rate in group I was $13.3 \%$ compared with $66.6 \%$ in group II $(p<0.01)$ who had a mean follow up of 13.4 months. Mortality 6 weeks following the index haemorrhage was $23.3 \%$ in group I with no bleeding related deaths (sepsis in 3, and 4 with hepato-renal failure). This was not significant when compared with the number of deaths in group II $(33.3 \%)$, although this group included 2 deaths due to rebleeding. Encephalopathy occured in 5 patients post TIPSS (16.6\%)

CONCLUSION: Rebleeding from gastric varices is significantly lower in patients treated with TIPSS as compared with those treated differently. TIPSS can be performed successfully in this group of patients who frequently are not fit to undergo surgery. We currently consider TIPSS as the tretment of choise for bleeding gastric varices. 
F257

DIRECT MEASUREMENT OF POST-PRANDIAL PORTAL HAEMODYNAMICS.

Stanley A.J., Forrest E.H., \#Redhead D.N., Hayes P.C. Departments of Medicine and \#Radiology, Royal Infirmary of Edinburgh, EH3 9YW.

Post-prandial changes in portal haemodynamics have been reported using derived methods or doppler ultrasonography. The presence of TIPSS allows direct assessment of portal venous response to a protein meal.

Methods: We assessed the portal and systemic haemodynamic response to a protein meal in 10 cirrhotic patients with TIPSS in situ (mean age 60.2 (3.7) years, mean Childs-Pugh score $7.8(0.6)$ ). Portal venous pressure (PVP) and flow (PVF) (measured by direct reverse thermodilution method with double thermistor catheter inserted in portal vein), right atrial pressure (RAP) and mean arterial pressure (MAP) were recorded whilst fasting and every 15 minutes for one hour following a $505 \mathrm{kcal}$. protein based meal. Pre- and postprandial portal venous blood gas measurements were obtained. Results: The maximal change in haemodynamic parameters from fasting levels are shown below. All measurements returned to normal 60 minutes following the meal and there were no significant changes between pre- and post-prandial portal venous blood gas analyses.

\begin{tabular}{|l|l|l|l|l|}
\hline & MAP & RAP & PVP & PVF \\
\hline Fasting: & $79.5(2.6)$ & $1.9(0.8)$ & $9.9(1.2)$ & $1137.7(162.1)$ \\
\hline Post-prandial: & $78.8(1.9)$ & $2.6(0.7)$ & $13.0(1.3)$ & $1642.2(256.6)$ \\
\hline p. value: & NS & NS & $\mathrm{p}<0.001$ & $\mathrm{p}<0.01$ \\
\hline
\end{tabular}

Results are expressed as mean (standard error). Pressures are shown in $\mathrm{mmHg}$ and flow in $\mathrm{ml} / \mathrm{min}$.

Conclusion: After a protein meal, PVP and PVF increase significantly whilst MAP and RAP remain unchanged. This technique allows direct assessment of therapeutic strategies to reduce postprandial hyperaemia.
Audit (upper GI tract) F259-F264 F259

INDICATIONS FOR MAINTENANCE ACID SUPPRESSION AT THE GENERAL PRACTICE/HOSPITAL INTERFACE

P Connor ', A McDonald *, D N Lynch *, P P Garratt *, C D Gillen ${ }^{1}$

Gastroenterology Department, RNH Haslar" and Stoke Road Surgery", Gosport,Hampshire PO12 1PA

Introduction: Repeat prescription of $\mathrm{H} 2$ receptor antagonists (H2RA) and proton pump inhibitors (PPI) in gastroesophageal reflux disease (GORD) and peptic ulcer is commonplace and expensive.

Aim: We sought to determine the indication for maintenance acid suppressive therapy at the general practice/ hospital interface.

Method: We examined the GP case records of 312 patients on long term acid suppression representing $4 \%$ of the total practice list $(8,185)$ and consuming $11 \%(\{69,000)$ of the total annual drug budget $(£ 640,000)$.

Results: 246 patients (79\%) had GORD, 46 patients duodenal ulcer (15\%) and 20 patients gastric ulcer (6\%). Thirty-one of the 66 peptic ulcer patients $(47 \%)$ had been tested for $H$. pylori, (13 positive).

The diagnosis was established by gastroscopy in 218 patients (70\%) and barium meal in $13(4 \%)$. Neither investigation had been undertaken in the remaining 81 patients (26\%).

The median age at the start of treatment was $62 \mathrm{yrs}$ (range 6-97yrs) and 44 patients were over 80 yrs. 203 patients used H2RA's (65\%) and 109 patients PPI's (35\%). The median duration of treatment was 4 years (range 1-20yrs).

Conclusion: Scrutiny of GP records is likely to identify examples of the over-prescription of maintenance acid suppressive therapy and should be a prerequisite to assessing the impact of alternative therapeutic strategies in the management of GORD and peptic ulcer.
ARTIFICIAL NEURAL NETWORK VS MULTIVARIATE LOGISTIC REGRESSION ANALYSIS FOR THE PREDICTION OF EARLY MORTALITY AFTER TIPSS FOR VARICEAL HAEMORRHACE ${ }^{1} \mathrm{Jalan} R$, ${ }^{1} \mathrm{Ala}$-Korpela $M$, ${ }^{2}$ Hiltunen Y, ${ }^{3}$ Redhead DN, 'Stanley AJ, ${ }^{3} \mathbf{E}$ ton RA, 'Bell JD, ${ }^{4}$ Hayes PC. ' $N M R$ Unit. Hammersmith Hospital, London, ${ }^{2}$ Raahe Institute of Computer Engineering. Finland: ${ }^{3}$ Department of Radiology and ${ }^{4}$ Medicine, and 'Statistics Unit, Royal Infirmary Edinburgh, UK. Backsround and Aims: TIPSS for variceal haemorthage is followed by deterioration in liver function tests and early mortality in about 20 $30 \%$ patients. The purpose of this study was to compare the performance of a trained Artificial neural network (ANN) with the model based upon multiple logistic regression (MLR)

Methods: Over a four-year-period 82 consecurive patients undergoing TIPSS for variceal haemornhage were studied. They were divided into two groups. Group I (66 patients) comprised the patients that were used to train the ANNs and establish the model based upon the results MLR. Group II (16 patients) comprised the patients that were used in a blinded manner to assess the trained neural network and also the MLR ANN: A feed-forward fully-connected ANN with 10 hidden neurons (DynaMind ${ }^{\mathrm{TM}}$ ) was trained with the 25 clinical variables related to clinical or biological data obtained from patients in Group I (input) to predict early mortality (output)

MLR: Significant independent predictors (sodium; $p<0.001$ and Pugh score $p<0.001$ ) were combined using the formula: $p=e^{x}$ $1+e^{x} ;$ where $p$ is the predicted probability of survival and $x=13.42$ $0.1429 \mathrm{X}$ [sodium] $+0.445 \mathrm{X}$ [Pugh score]

This network and the MLR model were then applied to predict early mortality of patients in Group II

Results: Sensitivity and specificity for predicting early mortality were $100 \%$ and $87.5 \%$ for the ANN and $25 \%$ and $93.8 \%$ for the MLR, respectively.

Conclusions: This study illustrates that ANN analysis can be useful in the prediction of early mortality before TIPSS is inserted, using routine clinical and biochemical parameters. Moving from the assessment of outcome by current methods towards ANN analysis will require similar comparisons, prospective evaluation and an open mind.
H. PYLORI SEROLOGY IN THE INVESTIGATION OF DYSPEPSIA: A GENERAL PRACTICE BASED FOLLOW-UP STUDY. T.G. Reilly, D Stone, V Poxon, TSJ Elliott, RP Walt. University Department of Medicine, Queen Elizabeth Hospital Birmingham.

Introduction: H. pylori serology has been proposed as a screening tool to focus endoscopy resources in young dyspeptics. We offer ELISA focus endoscopy resources in young dyspeptics. We offer E.

Methods: Patients identified from a serology database were followed by Methods: Patients identified from a serology database were followed by
examination of GP records for data on investigation, diagnosis, and $H$. pylori eradication therapy (ET). Prescriptions for antisecretory treatment and number of GP consultations were the outcome measures.

Results: From 1262 patients whose blood was tested for $H$. pylori over 14 months we examined the GP records of 958 . 220 patients whose serology was performed after investigation are excluded from this analysis. $738 \mathrm{had}$ either no investigation (406) or investigation following serology (332):

\begin{tabular}{|c|c|c|c|}
\hline \multirow[t]{2}{*}{$\underset{n}{\text { Diagnosis }}$} & \multirow{3}{*}{$\begin{array}{c}\text { Hp } \\
\text { serology n } \\
(\mathrm{P} \text {-pos) }\end{array}$} & \multicolumn{2}{|c|}{$\begin{array}{l}\text { Had eradication therapy } \\
n( \pm S D)\end{array}$} \\
\hline & & Yes & \\
\hline \multirow[t]{2}{*}{$\begin{array}{l}406 \text { none } \\
\text { (no tests) }\end{array}$} & & $\begin{array}{ccc}113 & =0.6 \quad( \pm 1.0) \\
r & =42 \quad( \pm 77)\end{array}$ & $44 \begin{array}{ll}c=0.42 & ( \pm 0.63) \\
r=39 \quad( \pm 66)\end{array}$ \\
\hline & $249 N$ & $\begin{array}{cl}5 & c=0.96( \pm 0.65) \\
& {[=33 \quad( \pm 20)}\end{array}$ & $\begin{array}{rl}244 & c=0.39( \pm 0.87) \\
r & =47( \pm 79)\end{array}$ \\
\hline \multirow{2}{*}{$\begin{array}{c}269 \text { non } \\
\text { ulcers } \\
\text { (after } \\
\text { tests) }\end{array}$} & $189 \bar{P}$ & 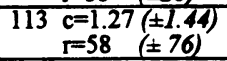 & $\begin{array}{cl}76=0.83( \pm 0.94) \\
r=60 \quad( \pm 92)\end{array}$ \\
\hline & $80 \mathrm{~N}$ & 1 & 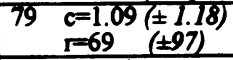 \\
\hline \multirow[t]{2}{*}{63 ulcers } & $60 \mathrm{P}$ & $\begin{array}{cl}56 & \mathrm{c}=0.50( \pm 0.82) \\
& =46 \quad( \pm 88)\end{array}$ & 4 \\
\hline & 3. & & 2 \\
\hline
\end{tabular}

Of 406 seropositives 282 received ET, $118(29 \%)$ without further investigation. 124(43\%) of those receiving ET had a further test to confirm success. In the 332 undergoing investigation there were 63 ulcers (3 success. In the 332 undergo 2 gastric cancers (>50) Nather the differences between non-ulcer patients (NUP) who did and did not have ET nor those between seronegative and seropositive NUP were sipnifican for either outcome measure. Seropositives who had no invectigation had fovwer prescriptions $(p=0.03$, Anova) and consultations $(p<0.0001)$ then either seropositive or seronegative NUP but not ulcer patients.

Conclusions: $29 \%$ of dyspeptics seropositive for Helicobacter received ET with no investigation. From our data, withholding endoscopy from seronegative patients under 50 would have missed $3.3 \%$ of ulcers. Treatment with ET was not beneficial in terms of lower consultation or prescription rates, in the absence of proven ulcer. 